\title{
Operários nordestinos na Região do ABC Paulista: narrativas de classe e de masculinidades
}

\author{
Jaime Santos Júnior (https://orcid.org/0000-0002-7809-6976), \\ Departamento de Sociologia e Programa de Pós-Graduação em Sociologia, \\ Universidade Federal do Paraná (UFPR), Curitiba, PR, Brasil'. \\ Mariana Zanata Thibes (https://orcid.org/0000-0002-6050-1160), \\ Universidade de São Paulo (USP), São Paulo, SP, Brasil". \\ Marilda Aparecida de Menezes (https://orcid.org/0000-0001-5815-975X), \\ Universidade Federal do ABC (UFABC), Santo André, SP, Brasil"'.
}

Resumo: Nesse artigo, recorremos à resultados de pesquisas feitas entre 1980 e 1984, 2012 e 2018, que analisaram, em um mesmo cluster, trajetórias de trabalho e migração de camponeses que deixaram o sertão da Paraíba para se inserir nas indústrias automotivas da Região do $A B C$ Paulista na segunda metade do século XX, estabelecendo um novo objetivo: arriscar o exercício metodológico de rever o conteúdo das entrevistas para pensá-las na chave da construção das masculinidades. Aspecto que emergiu da continuidade da pesquisa nos últimos anos e do desdobramento interpretativo dos achados que tínhamos em mãos. Os resultados sugerem que a pretensão do recorte longitudinal, que acompanha essas trajetórias de vida, sob o efeito de uma nova abordagem, realçou os aspectos do modo como operam as clivagens no interior de uma classe de trabalhadores desvelando as ambiguidades da construção da dignidade do trabalhador em um contexto de intensa exploração.

Palavras-chave: Memórias. Trabalho. Migração. Masculinidades. ABC Paulista.

\section{Northeastern workers in the ABC Paulista region: class and masculinity narratives}

Abstract: In this paper we used the outcomes of two researches carried out between 1980 to 1984 and 2012 to 2018 which analyzed, in the same cluster, work trajectories and migration of peasants who left Paraiba State to became workers at the automotive industries in ABC Paulista during the second half of the 20th century, establishing a new objective: to assume the methodological exercise of reviewing the interviews to think about them under the analytical key of masculinities. This issue has emerged from the continuity of the research in recent years besides the interpretive development of the findings we had in hand. The results that the longitudinal analyses which fol-
Recebido: 20.08.20 Aprovado: 29.04 .21
I. Jaime Santos Junior é professor do Departamento de Sociologia e do Programa de Pós-Graduação em Sociologia da UFPR. Doutor em sociologia pela Faculdade de Filosofia Letras e Ciências Humanas da USP. <jaimesjr@ufpr.br>.

II. Mariana Zanata Thibes é doutora e mestre em sociologia pela USP, com estágio na New York University. <mthibesster@gmail. com>.

III. Marilda Aparecida de Menezes é PhD pela University of Manchester, professora visitante nacional sênior (Capes/PVNS) da (UFABC) desde novembro de 2012 Pesquisadora do CNPq, nivel $1 \mathrm{C}$. <menezesmarilda@ gmail.com>. 
lows these life trajectories, under the effect of a new approach, highlighted some aspects which operate as cleavages within a class of workers, unveiling the ambiguities in self presentation of worker's dignity in a context of intense exploitation.

Keywords: Memories. Work. Migration. Masculinities. ABC Paulista.

1. Ao longo desse tempo, os projetos incorporaram diferentes pesquisadores, o que permitiu abrir novas frentes de investimento analítico e alargar o alcance teórico dos achados originalmente colhidos. Ver, por exemplo, Cover (2015).

\section{Primeiras palavras}

E ste artigo se vale de achados de pesquisa que vêm sendo realizadas desde a década de 1980 com trabalhadores(as) que migraram de áreas rurais da Paraíba para trabalhar em indústrias no estado de São Paulo, ou em usinas de cana-de-açúcar no estado de Pernambuco ${ }^{1}$. A primeira incursão em campo, ocorrida entre 1980 e 1984, resultou em dissertação de mestrado (Menezes, 1985), cujos objetivos eram compreender as estratégias de migrações de indivíduos que saíam do sertão paraibano para encontrar a sobrevivência no atraente e disputado mercado de trabalho das indústrias automotivas do ABC Paulista. A pesquisa insere-se na fortuna crítica de estudos que se debruçaram sobre as migrações de trabalhadores do Nordeste para o Sudeste, notadamente São Paulo e Rio de Janeiro, pensando-as enquanto processos de manutenção e reconversão de estratégias de vida. Os avanços desse primeiro trabalho permitiram, em outro momento, incorporar na análise deslocamentos de trabalhadores da mesma região para o corte de cana em Pernambuco (Menezes, 2002), para pensar a teia de formas de resistência que se constituem na experiência adquirida com esses deslocamentos.

Nesse longo percurso, entrevistamos e realizamos observação etnográfica com homens e mulheres que migraram e com os membros da família que ficaram nas localidades de origem, no entanto, ao rever estes primeiros investimentos, percebemos que os sujeitos que privilegiamos foram, principalmente, os homens; analisando suas experiências ocupacionais em indústrias metalúrgicas da Região do ABC Paulista e a de cortadores de cana em usinas de São Paulo e Pernambuco, setores de atividade econômica que empregavam majoritariamente homens.

Ainda debruçados sobre essas análises, notamos que a categoria mais recorrentemente mobilizada foi a de classe, com foco nos modos de vida, transformações das relações/condições de trabalho e de deslocamentos migratórios. Eram trabalhadores e famílias camponesas que se dedicavam ao cultivo de culturas alimentares, criação de animais e, devido às dificuldades de reprodução social, saíram de suas localidades para trabalhar como assalariados nas usinas de cana-de-açúcar e/ou em indústrias da Região Sudeste. É importante ressaltar que, embora o conceito de classe remeta a uma dimensão socioestrutural das relações econômicas no sistema 
capitalista, que certamente "emolduram" as relações de trabalho que procuramos observar, as análises tentaram privilegiar aspectos menos comumente observados pela literatura da época, tais como elementos da identidade dos trabalhadores, de seus valores e de sua moralidade.

Nas narrativas registradas através dos métodos etnográfico e da história oral, percebe-se como os trabalhadores migrantes construíam autoimagens que valorizavam a força física, a disposição, a disciplina para fazer qualquer tipo de trabalho, habilidades e interesse para aprender atividades novas. No caso dos que trabalhavam nas usinas de cana-de-açúcar, aqueles atributos eram constituintes da identidade dos trabalhadores "de fora", no caso, os "paraibanos", que contrastavam com os trabalhadores locais "pernambucanos", que eram representados por aqueles, assim como pelas chefias, como de menor produtividade, indisciplinados, acomodados e demandantes de direitos. Como observa Michèle Lamont (2000), em sua pesquisa com trabalhadores blue collar norte-americanos, a percepção do próprio valor advém de sua habilidade de autodisciplina e responsabilidade com o trabaIho. Nesse sentido, os padrões morais - e, podemos acrescentar, a própria constituição da masculinidade - funcionam como alternativa às definições puramente econômicas de sucesso, oferecendo-Ihes uma forma de manter a dignidade. Esses padrões servem não apenas para definir quem eles são, mas para diferenciá-los de outros trabalhadores, por meio de segmentações de classe, etnia e região de origem.

Entre os trabalhadores migrantes, que estavam nas indústrias da Região do $A B C$ Paulista, os atributos de força física, a disposição e a disciplina para fazer qualquer tipo de trabalho conformavam uma construção identitária de "bons trabalhadores", que compensava, de certo modo, sua condição de trabalhadores "em desvantagem" por serem provenientes do trabalho agrícola e com formação escolar primária, ou iletrados, sem qualificação profissional para o mercado de trabalho industrial e urbano. As narrativas evidenciavam marcadores de classe, mas também de gênero, ou seja, atributos que fundamentam e afirmam uma construção identitária masculina. No entanto, a chave analítica da "masculinidade" não foi mobilizada nessas primeiras pesquisas.

Em 2013, houve a possibilidade de retomar o contato com alguns entrevistados, dando início a uma nova agenda de pesquisa², passados mais de 30 anos da realização do primeiro contato com o grupo de trabalhadores originariamente analisados. Com efeito, novas entrevistas foram realizadas com esses e outros migrantes que permaneceram na Região do $A B C$, ou que retornaram aos seus municípios na Paraíba. Esse contato permitiu explorar novas dimensões de análise, como as rela-
2. No âmbito de dois projetos de pesquisa:

i. "Memórias de trabalhadores

migrantes nordestinos na Região do $A B C$ Paulista: 19501970", trabalho desenvolvido entre outubro de 2012 e outubro de 2018, financiado por uma bolsa de professor-visitante sênior (PVNS/Capes/ UFABC);

ii. "Ambivalências e disjunções em transmissões intergeracionais: trabalhadores nordestinos no ABC Paulista", desenvolvido entre 2015 e 2016, com financiamento do CNPq, na forma de bolsa de pósdoutorado. 
ções de gênero (Thibes, Menezes \& Santos Júnior, 2018) e a construção de masculinidades. Essas duas ideias nos pareceram centrais tanto ao revisar as entrevistas mais antigas, quanto na consecução de novas análises, constituindo uma forma de conectar experiências temporalmente distantes.

Animados por esse desafio, propomo-nos implementar, neste artigo, um duplo movimento: por um lado, retornamos às primeiras narrativas colhidas há 30 anos no afã de analisar como a produção de masculinidades foi elaborada pelos trabalhadores que migraram de áreas rurais da Região Nordeste para cidades industriais de São Paulo. São pessoas que nasceram entre as décadas de 1940 e 1960 e vieram para a Região do ABC Paulista nas décadas de 1960 e 1970. Em sua maioria, se inseriram em indústrias metalúrgicas, pertencendo ao grupo que se reconhece e é reconhecido como "os metalúrgicos do ABC" (Tomizaki, 2005).

Procuraremos também analisar como a construção de atributos de masculinidade está entrelaçada com a proveniência, ou seja, por serem da Região Nordeste do Brasil e identificados como "nordestinos". Não resistimos à pista deixada por Hernán Palermo (2017) que, pesquisando em outro contexto, chama atenção para esse aspecto,

\footnotetext{
Varios estudios afirmaron que no solo es necesario abordar las masculinidades desde una perspectiva de clase, sino también a partir de una relación generacional, de etnia y región, para acceder a una comprensión particular tanto histórica como social (Palermo, 2017: 25).
}

O conjunto de entrevistas apresentadas foram feitas com agricultores da microrregião do Sertão de Cajazeiras, Paraíba, que migraram para a Região do ABC Paulista nas décadas de 1960 e 1970. Por outro lado, e para ir além, colhemos novos relatos. Sendo assim, as entrevistas foram realizadas em dois períodos, de 1980 a 1984 (Menezes, 1985), período em que eram trabalhadores que estavam na fase produtiva da vida, inseridos no mercado de trabalho - a maioria contava entre 20 e 40 anos - e, após 30 anos, no período que vai de 2012 a 2018 (Thibes, Menezes \& Santos Júnior, 2018; Santos Júnior, Thibes \& Menezes, 2019), com alguns trabalhadores que foram entrevistados na década de 1980 e outros. Para esta última fase, as entrevistas foram com trabalhadores - homens e mulheres - que estavam na fase de aposentadoria. O trabalho não era mais o centro do cotidiano de suas vidas, todavia, em suas memórias, é narrado como sendo uma experiência central no ciclo de vida. 


\section{Arranjos metodológicos}

Parecia claro o risco que assumiríamos ao retornar aos achados de pesquisas coIhidos em diferentes momentos, ainda que com objetivos muito próximos. O fio da navalha nos tocava pelo viés do anacronismo, fecundando narrativas colhidas outrora com questões que nos inquietam no tempo presente. Mas consideramos que seria possível calibrar esse retorno, aproximando os achados de pesquisa por meio do seguinte artifício. Em termos metodológicos, o desafio proposto mira dois alvos:

i. rever o material colhido em campo inserindo uma nova chave de interpretação, a da construção de masculinidades; e

ii. o faz por meio de um desenho longitudinal, que retorna a campo para fazer entrevistas com o mesmo grupo de trabalhadores.

Não se trata, pois, de um estudo de painel, que demandaria maiores restrições na composição do universo dos casos analisados, mas sim de cluster, por considerar que o grupo de trabalhadores que nos interessa apresenta características internas semelhantes, mas distintas quando comparados a outros grupos. Importa dizer que são trabalhadores com origem rural, que comungam de um modo de vida próprio, com hábitos e valores que nos permitem circunscrevê-los em um cluster. Portanto, na seleção dos casos, não se exigiu que fossem os mesmos entrevistados há 30 anos. No Quadro 1, abaixo, reunimos alguns dados objetivos para facilitar a compreensão dos casos que selecionamos.

\section{QUADRO 1}

DISPOSIÇÃO DAS ENTREVISTAS

\begin{tabular}{lcccc}
\hline \multicolumn{1}{c}{ Nome fictício } & Ano de nascimento & $\begin{array}{c}\text { Ano da migração } \\
\text { para a Região ABC }\end{array}$ & Ano da entrevista & Local da entrevista \\
\hline Aldo Lemos & 1958 & 1974 & 1984 & São Bernardo do Campo/SP \\
Geraldo Lemos & 1918 & - & 1983 & Bonito de Santa Fé/PB \\
José Ramos & 1959 & 1974 & 2014 & São Caetano do Sul/SP \\
Joaquim Bernardo & 1950 & 1967 & 1983 & São Caetano do Sul/SP \\
Marcos Silva & 1956 & 1978 & 1983 & Santo André/SP \\
\hline Fonte: elaboração própria. & & & &
\end{tabular}

Ao citar os fragmentos de entrevista, identificaremos a idade no momento da entrevista e o ano de sua realização. Para melhor organizar os achados, estruturamos a argumentação em três partes: a primeira analisa como os atributos de masculinidade, tais como força, disciplina e disposição para o trabalho estão associados ao termo nativo "coragem". Na segunda, interessa-nos os modos de veiculação de 
uma imagem de "macho", como valor moral, enquanto atributo do "nordestino". Por fim, exploramos os elos existentes entre as identidades de ser "macho" e "nordestino" como elementos disposicionais (Bourdieu, 1998) mobilizados para aguentar a humilhação e o sofrimento no cotidiano do trabalho.

\section{"Coragem": \\ força, disciplina e disposição para o trabalho}

Do amplo movimento que mudou a face do Brasil, sabemos hoje que as migrações entre a Região Nordeste e São Paulo se intensificaram na década de 1950 (Lopes, 1967; Fontes, 2008) propiciando o fluxo de pessoas, mercadorias e notícias, ativando, no imaginário social, a imagem de São Paulo como lugar de emprego fácil, onde se ganhava muito dinheiro e havia facilidade para "comprar um terreno" e construir a casa própria. Circulavam, também, notícias da dureza do trabalho e da vida, das extensas jornadas de trabalho, sob os auspícios da quase obrigatoriedade de se fazer horas extras. Mais detidamente, o setor industrial da Região do ABC Paulista demandava trabalhadores com "força física", com "disposição" para todo tipo de trabalho, com o acréscimo de serem "disciplinados", ou seja, que fossem capazes de cumprir as regras de controle estabelecidas pelas fábricas (Negro, 2004).

A questão que nos orienta aqui é analisar se, nas narrativas dos trabalhadores procedentes de áreas rurais da Região Nordeste, emergem construções de si mesmos como homens com força, disciplina e disposição para o trabalho, e de que modo tais representações reverberam em pilares fundamentais não apenas do que é "ser homem", mas do que é ser um homem com valores, qualidades e dignidade que o distingue de outros e, nesse sentido, compõe um elemento fundamental de sua identidade. Compreendemos que os textos gerados a partir das entrevistas são narrativas, nos termos propostos por Verena Alberti (2004).

\footnotetext{
Ao contar suas experiências, o entrevistado transforma aquilo que foi vivenciado em linguagem, selecionando e organizando os acontecimentos de acordo com determinado sentido. Esse trabalho da linguagem em cristalizar imagens que remetem a, e que significam novamente, experiência é comum a todas as narrativas (Alberti, 2004: 77, grifos nossos).
}

É através da linguagem que a experiência passada é organizada e significada. Assim, a linguagem é, ela mesma, ato, produção de algo. A narrativa não é um relembrar fiel do passado, mas sim uma ressignificação do passado a partir do presente (Bosi, 1994; Halbwachs, 2006). Ou, como propõe Alessandro Portelli (1997): 
Mas o realmente importante é não ser a memória apenas um depositário passivo de fatos, mas também um processo ativo de criação de significações. Assim, a utilidade específica das fontes orais para o historiador repousa não tanto em suas habilidades de preservar o passado quanto nas muitas mudanças forjadas pela memória. Estas modificações revelam o esforço dos narradores em buscar sentido no passado e dar forma às suas vidas, e colocar a entrevista e a narração em seu contexto histórico (Portelli, 1997: 33).

Os narradores tecem os fios entre o presente e o passado para dar forma e sentido às suas vidas. No mesmo compasso, Rita de Cássia Paiva (1999) sugere que narrar é unir descontinuidades, ou seja:

O narrador ou o investigador, ao reescrever a ação e o discurso que the é inalienável, conectando seus fragmentos, efetua uma transcrição significativa. Esta não enuncia verdades sobre a ação, mas visa a dialogar tanto com o objeto (sujeito) quanto com as outras teorias que abordem o assunto sobre o prisma de uma outra racionalidade (Paiva, 1999: 98).

Imbuídos desse partido teórico, analisaremos fragmentos das narrativas dos trabalhadores migrantes de modo a propor um argumento para o nosso objeto de estudo; dito de outro modo, perseguimos o desafio de compreender como os trabalhadores migrantes de áreas rurais que se tornaram operários em metalúrgicas constroem suas identidades fundamentadas em referenciais de masculinidade cujos elementos partem de suas experiências no mundo do trabalho e/ou de sua origem regional. Vejamos.

Nosso primeiro personagem é Aldo, nascido em 1958, casado, três filhos, entrevistado em 1984, quando tinha 26 anos. Seus pais eram agricultores, possuíam uma pequena propriedade no município de Bonito de Santa Fé, Paraíba. Na ocasião do nosso encontro, tinha onze irmãos, sendo ele o décimo filho. O irmão mais velho contava 42 anos em 1984 e foi o primeiro a migrar para a Região do ABC Paulista, em 1970. Na sequência vieram outros sete irmãos, os demais ficaram no município de origem. Para se referir aos ensinamentos dos pais Aldo diz:

Todo mundo do Norte [Norte é um termo recorrente para se referir à Região Nordeste] achava bom lá. Houve 70 [1970] que foi seco, aí vem muita gente embora, aí depois de 70 o povo vinha, escrevia prá lá [Paraíba] ou ia passear lá e falava que aqui [São Paulo] era bom, que o cara trabalhava e ganhava muito dinheiro. Este povo que contava papo acho que tinha vergonha, porque tinha saído do Norte, queria voltar bem. Meu pai sempre dizia que pra quem é novo e tem coragem de trabalhar, São Paulo é bom 
para viver, mas, pra quem não tem coragem de trabalhar, não dá não (grifos nossos, entrevista de 1984).

Coragem é um sintagma que aparece com recorrência tanto nas narrativas dos que migraram, quanto dos que ficaram na Região Nordeste, como veremos ao longo da exposição. Ele sintetiza alguns atributos do trabalhador - recordando, o ser "forte", "disposto" para todo tipo de trabalho e "disciplinado". São elementos, notem, de ordem moral, não sendo meramente um atributo físico. Em entrevista feita com o pai de Aldo, Geraldo, à época com 65 anos, em outubro de 1983, em sua casa na área rural do mesmo município, ele volta a mobilizar o termo coragem para designar um atributo de caráter dos que migram para São Paulo.

Por que o pessoal sai para São Paulo?

É um ato de coragem, porque o camarada sai daqui prá enfrentá a vida lá, é coragem. Porque se ele não tiver coragem, ele não sai (entrevista de 1983).

Na sequência, ao relatar sobre as condições de trabalho, renda e vida na agricultura em comparação com São Paulo, ele diz:

Eu acredito que o São Paulo é melhor do que aqui, se eu fosse um homem novo eu não tava aqui, eu tava em São Paulo. Porque lá [SP] trabalha, o que eu falo sempre é assim, que se aqui [Paraíba] todo mundo trabalhasse como o que vai prá São Paulo trabalhar, as condições daqui [Paraíba] era diferente, lá [São Paulo] trabalha de dia e de noite (grifo nosso, entrevista de 1983).

Nesse fragmento, observamos como o atributo de "coragem" está associado a um componente geracional, ser "homem novo". Eis que Geraldo tem coragem, disposição e força para trabalhar, todavia, já não é mais jovem para enfrentar a dureza do trabalho fabril. As notícias sobre as regras de controle e disciplina do trabalho circulavam nos territórios de origem dos trabalhadores. A expressão "trabalhá de dia e de noite" evidencia como as condições de intensa exploração do trabalho em São Paulo, seja pela extensão da jornada, ou da intensidade, deixa-se entrever nas representações não apenas dos que migram, mas também dos que ficaram nas áreas rurais da Região Nordeste.

É com esse espírito que Aldo migra para São Bernardo do Campo, em 1979, almejando trabalhar na indústria, assim como seus irmãos, sonhando ganhar um bom salário e ascender na carreira profissional. No entanto, como a maioria dos migrantes (Fontes, 2008), seu primeiro emprego foi na construção civil. Passados três meses, resolve retornar para sua terra e trabalhar na agricultura. O que é assim narrado. 
Voltei porque trabalhar no pesado, de construção, era melhor viver no Norte mesmo. Fiquei de 1979 a 1982 trabalhando na agricultura, voltei [para São Paulo] em fevereiro de 1982. Vim sozinho, a família veio em junho de 1982. Não veio tudo de uma vez, porque a condição de dinheiro não dava pra vir tudo de uma vez. Cheguei e enfrentei outra construção, com treze dias meu irmão arrumou [emprego] na fábrica (entrevista de 1984).

Em sua segunda vinda a São Bernardo do Campo, em 1982, o primeiro emprego foi novamente na construção civil. Mais uma vez ele recorre à noção de "coragem", traduzida em ser trabalhador "forte", disposto a todo tipo de trabalho - "de dia e de noite" - como eixo central de sua narrativa.

Porque tem muita gente, nordestino, que tá desempregado há muito tempo, mas não volta, passa o tempo todo vivendo de bico.

Eu mesmo, quando eu cheguei do Norte, eu falei: o primeiro serviço que eu encontrar eu pego. Aí eu cheguei na casa da minha irmã e falei: vou arrumar um serviço pra mim aqui.

- Ah! Você não tá doido não?

Eu digo: olha, quem tá sabendo como o sapato tá apertando é eu. Deixei minha família no Norte e tô precisando trabalhar prá mode ajudar a família. Aí eu cheguei lá e falei: tá pegando ajudante?

- Tá, você tem coragem?

Eu digo: mas rapaz, que é isso! Eu tenho a coragem de enfrentar tudo no mundo, rapaz. Aí ele falou:

-Tão magro e tão baixinho, eu acho que você não vai aguentar, não.

Eu falei: mas se engana, tu tá enganado.

Ele falou: tá, tudo bem, amanhã traga sua carteira e você vem aí.

Aí no outro dia eu cheguei, eles já me deram uma roupa, me deram um capacete e disse: não, você já começa a trabalhar (grifos nosso, entrevista de 1984).

A observação do funcionário da empresa de construção civil, que realça o aspecto físico do nosso entrevistado, estabelece um contraponto para o perfil requerido do trabalhador, que precisava ter um corpo forte para enfrentar a labuta diária. Mas expressa também uma noção de masculinidade para designar que não basta ser homem, é preciso, além dos atributos físicos mencionados, performar um comportamento viril. O emprego do verbo "aguentar" não é casual. Como transitivo direto, requer um complemento, e é neste campo semântico que se assenta a maneira como Aldo reage à dureza do trabalho: "eu tenho a coragem de enfrentar tudo no mundo". Este é um elemento que ganha relevo em sua narrativa à medida que, a despeito de todas as adversidades da vida de Aldo, das ausências - falta de um corpo robusto, de 
dinheiro, de educação formal -, o predicado da coragem basta para que ele conquiste a sua dignidade e se torne um homem cheio de atributos valorados.

Como observa Lamont (2000), sobre a diferença entre os valores mais prezados por trabalhadores blue collar brancos e negros nos Estados Unidos, enquanto entre os primeiros há maior ênfase na disciplina, na responsabilidade e na franqueza, os últimos valorizam, além da responsabilidade e do trabalho duro, os valores mais "coletivistas" da solidariedade e da generosidade, como resultado de sua experiência de luta coletiva contra a discriminação racial. Este é um ponto importante porque mostra que os valores mais prezados por determinada categoria de trabalhador refletem também o contexto e as condições estruturais de sua vivência. No caso dos trabalhadores nordestinos aqui retratados, a própria identidade de "nordestino" também servirá como cimento de solidariedades tecidas entre os trabalhadores com origem comum e que alimentará resistências contra os desmandos da fábrica; já a ênfase na força, na disposição e na disciplina revelam tanto um modo de se diferenciarem dos "paulistas", que não compartilhariam da mesma força e não seriam capazes de suportar o mesmo tipo de lide, realizando os trabalhos leves de "planejamento", quanto de fazerem frente à sua própria fragilidade.

Após 13 dias trabalhando na construção civil, indicado por um dos irmãos, Aldo conseguiu um emprego em uma metalúrgica de São Bernardo do Campo, inicialmente como ajudante de produção e depois como Caldeireiro. Se a construção civil era o primeiro emprego para a maioria dos migrantes nas décadas de 1960 e 1970, o desejo de todos era trabalhar na indústria, especialmente no setor metalúrgico, onde se esperava ter melhor salário e ascender na carreira profissional (Menezes, 2019). O trabalho na indústria representava para o migrante nordestino a possibilidade de adquirir uma profissão. A expectativa tinha como contexto a experiência de amigos e parentes (particularmente aqueles que migraram em décadas anteriores a 1970) que conseguiram adquiri-la. Em seu estudo sobre os migrantes nas fábricas automobilísticas do ABC na década de 1950, Antonio Negro (2004) também observa o desejo de entrar numa fábrica, especialmente a automobilística.

\footnotetext{
Um novo mundo se descortinava após o ingresso numa automobilística, e, de fato, o fenômeno da incorporação do migrante à indústria revestia-se de novos significados. No exercício fiscal anterior, entre os 582 empregados daquela "fervilhante colmeia de trabalho", era comum deparar-se com o operário de construção que acabara de encerrar o serviço da edificação dos galpões industriais (Negro, 2004: 411).
}

A valorização do trabalho na fábrica vem atrelado, o mais das vezes, a um projeto de ascensão na carreira e estabilidade, cujos signos externos de afirmação social 
envolvem práticas de consumo tais como adquirir terreno, casa, carro, itens reconhecidos e legitimados como símbolos de melhoria de vida. Mas há, também, o sentimento mais difuso de dignidade enquanto trabalhador que, brioso de sua "coragem", trabalhou duro para se construir como homem digno e honrado, bom trabalhador e pai de família. A ideia de sucesso para esses indivíduos, embora vinculada a atributos do mundo do trabalho, não é constituída apenas por elementos desse universo. Há um projeto de vida que tem como centro a família e no qual eles desempenham o papel de provedores, enquanto as mulheres se responsabilizariam pelo trabalho doméstico (Thibes, Menezes \& Santos Júnior, 2018). Esse arranjo já foi bastante discutido pela literatura no registro da ideologia patriarcal e da divisão sexual do trabalho (Safiotti, 1970). No entanto, pouco se atentou para o fato de que, do ponto de vista das necessidades dessas famílias, valoriza-se a situação da esposa que não precisa trabalhar em razão do salário auferido pelo marido e/ou fiIhos (French \& Cluff, 2000). Assim, o trabalho da mulher fora de casa era visto como uma exceção provocada por dificuldades econômicas ou pelo desejo da família de buscar mobilidade social ascendente.

Os trabalhadores provenientes de áreas rurais tinham a experiência do trabalho familiar, regido por outras normas e valores, enquanto o trabalho assalariado demandava nova socialização. A própria rede de parentes e conterrâneos já atuava como guia a esse respeito, alertando para as novas exigências requeridas. Mas é a valoração de atributos físico e de comportamento que salta à vista operando, como queremos arguir, na chave da construção de um ideal de masculinidade. Nesse sentido, Palermo (2017), no estudo que fez com sobre trabalhadores petroleiros na Argentina, é inovador ao analisar a produção de masculinidades na disciplina do trabalho.

La disciplina fabril no solo es considerada a partir de los atributos técnicos requeridos para el trabajo. También forma parte de los criterios que se evalúen las maneras de comportarse como hombres (Palermo, 2017: 78).

Ao estudar as identidades de duas gerações de metalúrgicos do ABC, Kimi Tomizaki (2005) encontra os mesmos elementos.

Se tomarmos as relações com o corpo como eixo para olhar essas duas gerações, rapidamente percebemos que há, de fato, um fosso entre esses dois grupos. A primeira geração, em sua maioria absoluta, tem origem rural e foi introduzida em um fábrica tipicamente fordista e taylorista. Trata-se, portanto, de trabalhadores formados pelo "trabalho pesado", que valorizam a força física como um recurso identitário importante. Além disso, os aspectos 
que definem sua masculinidade e virilidade são bastante visíveis tanto na forma tradicional de se vestir ou de cortar e manter o cabelo, quanto no cultivo dos hábitos de beber (geralmente cachaça) e fumar. A segunda geração, por sua vez, sendo constituída pela escola e gozando dos padrões de vida da classe média, apresenta uma outra relação com o corpo. A força física é mais eufemizada, o cuidado com as roupas, por exemplo, causa estranheza entre os mais velhos, além dos brincos, cabelos longos (ou cabeça raspada) e outros acessórios inimagináveis para a primeira geração, tais como anéis, pulseiras, colares e as inevitáveis tatuagens (Tomizaki, 2005: 21).

Os trabalhadores que entrevistamos nas duas etapas da pesquisa, no início da década de 1980 e entre 2012-2018, constituem o que Tomizaki (2005) identifica como sendo a primeira geração de metalúrgicos. Nos fragmentos que analisamos anteriormente, Aldo fala de sua "coragem" de enfrentar qualquer tipo de trabalho, em outros momentos da entrevista, a ideia de "coragem" é narrada não como sendo um atributo pessoal, mas constituinte da própria identidade do nordestino, vejamos o fragmento abaixo.

Prá começar, o nordestino é o seguinte: você sabe, que o que tiver aqui [São Paulo] ele tá pegando. O serviço que tiver, ele já... Porque você chegando do Nordeste aqui, então, prá começar ele não vai pegar serviço bom, ele vai ser ajudante numa firma. Ali então é toda vida de ajudante. Então chega aqui e a pessoa interessado em trabalhar, às vezes recebe seu salário prá dar à família... Aí fica trabalhando. Trabalha de dia e de noite direto (entrevista de 1984).

Vê-se como ele não fala propriamente de si, mas do trabalhador nordestino. É o nordestino, homem com coragem, "interessado em trabalhar" e provedor da família, com disposição para qualquer serviço.

Essa imagem do nordestino também emerge com ênfase na memória dos trabaIhadores que entrevistamos no período de 2012 a 2018, os quais eram força de trabalho ativa nas indústrias metalúrgicas da Região do ABC Paulista nas décadas de 1970-1980. É o caso de José Ramos, entrevistado em 2014, que nasceu em maio de 1959 no município de São José de Piranhas (PB). A primeira viagem ao município de São Caetano do Sul (SP) ocorreu em 1974, quando ainda tinha 15 anos, acompanhado da mãe que faria tratamento de saúde. Ficou na casa de sua tia, irmã da mãe, por três meses e depois retornou à Paraíba. Em 1976, com 17 anos, viajou novamente, agora acompanhado de um tio. De 1976 a 1978, trabalhou em indústrias pequenas, aguardando uma chance para conseguir uma vaga em uma indústria maior, preferencialmente automobilística. Em 1978, conseguiu uma vaga na Bom- 
bril e ficou até 1998. Entrou como "ajudante" e, em pouco tempo, foi promovido a "operador de máquina". Em suas memórias sobre o início da trajetória ocupacional nas indústrias do ABC Paulista, José Ramos mobiliza a termo "coragem" para dar relevo a uma "narrativa de si" (Ricœur, 1994) enquanto trabalhador com força física, disciplina e disposto para qualquer tipo de trabalho.

\section{Eles registraram como ajudante?}

Ajudante geral. Daí quando entrei lá dentro, aí comecei... Aí a gente vai desenvolvendo, sempre o nordestino ele tem coragem de trabalhar. E lá os trampo muito pesado, mas a gente foi indo, foi indo, até que me promoveram, me deram um aumento. Eu comecei tomar de conta de três máquinas. Aí de ajudante já passei a ser operador de máquina. Foi aí onde eu casei. Que eu casei eu estava na Bombril, só que depois que a minha filha nasceu houve uns fracasso, umas greve e eu e mais uns cara de nosso setor a gente saiu, foi mandado embora (José Ramos, entrevista de 2014, grifo nosso).

Observe-se que, junto à coragem para trabalhar aparece a imagem do que ele chama de "fracasso" e da demissão após a greve. É justamente para fazer face às inúmeras adversidades e necessidades que a "coragem" adquire lugar central na hierarquia de valores desses homens. O reforço desse valor moral, bem como a força e a disposição, constitui um recurso importante para transformar a "dificuldade em orgulho e a servidão em honra" (Rodgers, 1974).

A valorização do trabalhador nordestino pode ser situada no período em que a indústria automobilística, especialmente na Região do ABC Paulista, foi considerada o carro-chefe do desenvolvimento no Brasil, como nos explica Negro.

De fato, quando o Última Hora estampou a notícia da vitória na "batalha do automóvel nacional", esta era mais um sinal de sua afinidade com desejos presidenciais. A indústria automobilística já podia ser considerada uma realidade: seria o "carro-chefe" da expansão acelerada e ainda oferecia um belo horizonte ao eleitorado. Se o ABC Paulista viria a ser o seu reduto, na personagem do lavrador-sertanejo-migrante-operário, vicejava a imagem de um país - a um só tempo - economicamente forte e socialmente viável (Negro, 2004: 407).

Em outra passagem, o mesmo autor prossegue.

Ramificando essa aura de progresso com paz social - e para compor a figura do migrante-operário -, a construção de fábricas de motores a combustão visou ao saque de um aspecto bem comum 
na representação do "nordestino". Após visitar a fábrica da Willys do Brasil, o jornalista Ofir Pinheiro relatou: "ali [...] o sertanejo foi encontrar de novo a sua terra e, com o rosto ainda crestado pelo sol impiedoso do Nordeste, adere à máquina, integra-se nela e dela vê orgulhoso brotar o fruto que seus braços produziram" (Negro, 2004: 408).

Esse texto do jornalista Ofir Pinheiro foi publicado em O Jornal do Rio de Janeiro, em 4 de fevereiro de 1960. Essa imagem do nordestino já vinha sendo construída desde a década de 1950 pela imprensa, pelos políticos e empresários do setor automobilístico. É exemplar uma frase de uma crônica sobre o nordestino em uma publicação intitulada "Vida na General Motors do Brasil", de 1950: "O cearense não cede; é valente e não se dá por vencido..."

Em ambos os textos, é interessante observar que a descrição do "sertanejo" e do "cearense" remetem a atributos masculinos, como homem forte, cujo corpo, marcado pelo sol impiedoso do Nordeste, confunde-se com a máquina, orgulhando-se do fruto de seu corpo. A origem rural é enaltecida invertendo a imagem recorrente do Nordeste como região da seca, da fome e do atraso, para emprestar-lhe um sentido de berço de homens com corpos fortes e mão de obra disponível para o moderno setor industrial. É assim que José Ramos, apesar de se lamentar por ser iletrado e não ter qualificação para o que a indústria demandava, valoriza os elementos da sua socialização na roça, onde aprendeu a "trabalhar pesado".

Eu tive todas as firmas que trabalhei, eu sempre tive um ambiente bom porque eu sou, eu vim da roça, a pessoa que enfrenta uma roça, ele chega aqui, tem trampo pesado? Tem, mas a pessoa trabalha, eu tive meu ambiente bom, é tanto que eu com quatro meses que eu tava na Bombril recebi uma promoção já de operador de máquina. Entrei como ajudante geral, que eu não sabia ler, então, foi assim.

Você chegou aqui sem saber ler?

Eu só sabia fazer meu nome e mal, então meu ambiente era muito bom. Era um cearense que era meu mestre, Luís o nome dele, o cara me deu toda força, ele viu meu interesse e num instante eu tava operando as máquinas, chamava-se recuperador de material (José Ramos, entrevista de 2014, grifos nossos).

As pistas deixadas por outros estudos também atestam como essas imagens do migrante-operário, do trabalhador nordestino, incorporaram-se nas representações que os migrantes-operários elaboravam sobre si mesmos. Se, de um lado, essas imagens contribuíram para suprir os setores produtivos das cidades com a força de trabalho capaz de suportar a intensa e extensa jornada de trabalho, de outro, tor- 
naram-se um recurso cultural ${ }^{3}$ que contribuiu para que os trabalhadores migrantes não apenas se inserissem no mercado de trabalho mas, também, ascendessem na carreira profissional. No entanto, nem todos tiveram a experiência de mobilidade profissional, muitos não atendiam a esse perfil de trabalhador, outros se rebelaram, seja através de resistências silenciosas, invisíveis, no cotidiano da fábrica, ou através de suas expressões coletivas públicas, a exemplo das greves. Os que não se "adaptaram" retornaram para as suas localidades de origem.

Ao retomar a proposta que lançamos aqui - a de compreender como noções, imagens e atributos que se vinculam a um ideal de masculinidade emergem nas narrativas dos trabalhadores de áreas rurais da Região Nordeste que se tornaram operários na Região do ABC Paulista -, na próxima seção analisaremos alguns fragmentos de narrativas que enfatizam a condição de "macho" do nordestino.

\section{Nordestino é "macho"}

Para os casos que analisamos, vê-se como a socialização prévia no trabalho agrícola fornece os elementos que serão mais uma vez mobilizados discursivamente em outro contexto. Sendo assim, eles seriam treinados para o trabalho pesado, com jornadas longas e condições ambientais extenuantes como é o caso do trabalho rural no sertão. Ficamos sabendo que ter "coragem" é também estar disposto a enfrentar outras formas de organização e disciplina do trabalho, como sempre dizem: "o nordestino tem que aprendê a convivê com o próprio ambiente que vive". Esta sorte de saber-comum pode ser lida como uma espécie de "sabedoria", ou seja, incorporar as práticas, saberes e modos de lidar e driblar as regras de organização e controle do trabalho ${ }^{4}$. Enquanto em algumas narrativas a masculinidade se expressa como "coragem", força física, disposição para qualquer tipo de trabalho, em outras, a masculinidade emerge em linguagem mais explícita, como é o caso da construção da imagem do nordestino como "machão". Vejamos como isso aparece.

Joaquim Bernardo, que nasceu em 1950, migrou em 1967, aos 17 anos de idade, para o município de São Caetano do Sul, Região do ABC Paulista. A primeira entrevista que fizemos com ele ocorreu em 1984, quando já era metalúrgico, e, nessa ocasião, ele nos revelou o sonho de ser sindicalista. Em outro momento, na pesquisa realizada no período de 2012 a 2016, conseguimos o seu contato com uma de suas irmãs que nos forneceu seu telefone. Fizemos inúmeras tentativas, através de telefonemas, para agendar uma nova entrevista, após ter decorrido trinta anos do nosso primeiro encontro, no entanto, não obtivemos sucesso. Os motivos alegados foram os mais diversos, a falta de tempo, compromissos com a saúde, ou mesmo que não tinha nada de interessante para contar.
3. Para recorrer à ideia de "sistema cultural" como conjunto de proposições interdependentes que compõe um sistema mais amplo e que é visto na relação com as estruturas sociais e os agentes humanos Sistemas culturais e estruturas sociais influenciam-se mutuamente, mas somente na medida em que criam contextos de ação (capacitadores ou constrangedores), uma vez que dependem da atuação dos agentes para reproduzir ou alterar as condições estruturais e culturais em que estão inseridos. Sobre isso, ver Archer (1996).

4. Na mesma acepção do que Michel Certeau (1994) chamou de "táticas". 
Embora não tenhamos mais elementos que nos permitam compreender os motivos dessa recusa, ficamos apenas com a entrevista realizada em 1984, quando ele tinha 34 anos de idade. Na passagem que diz ter o sonho de ser sindicalista, ele mobiliza a imagem de nordestino "machão".

Você tava falando que em São Paulo, a maioria dos sindicalistas é nordestino. Por quê? O nordestino é mais de luta? Tem mais disposição de luta?

Acho que o nordestino tem mais, é mais macho, entende? Mais macho. Não é desprezando o paulista. Eu acho que o paulista é o melhor que tem de brasileiro, mas eu acho que o nordestino é mais macho. Tudo machão, a maioria dos homens são tudo machão. Não é que eles são machão, é o ritmo da terra. Sabe que lá no Norte, o paraibano principalmente, ele fala: "Eu sou homem, na minha casa quem manda sou eu". Na minha casa quem manda sou eu também, mas tem que combinar com a mulher. Então eu acho que não tem nada a ver, eu acho que tem que se entender e todo mundo mandar, né? Porque ninguém manda, quem manda somos nós. Porque numa casa quem manda é a família. O que eu, a minha mulher e a minha filha. Quem manda em casa realmente

5. John Humphrey (1983), em artigo que analisa a participação das mulheres no mercado de trabalho industrial e nos sindicatos, identifica que as diretorias dos sindicatos eram majoritariamente masculinas. Quanto à participação da mulher, considera que é um processo difícil, em parte devido à resistência dos homens, um tanto em razão da debilidade das posições feministas na classe operária naquele momento.

\section{Os migrantes} utilizavam com frequência o termo "Norte" para se referir à Região Nordeste do Brasil. Porém, ao falar das pessoas, é mais corrente o termo nordestinos. mesmo eu acho que é minha filha (Joaquim Bernardo, entrevista de 1984).

Em sua narrativa, observamos que a ideia de "machão" é mobilizada como recurso para marcar a diferença entre espaços sociais distintos, tais como o sindicato, a empresa e a família. O fragmento acima está em um contexto no qual ele relatava que a maioria dos dirigentes sindicais era composta por nordestino ${ }^{5}$. Interessante observar que Joaquim Bernardo estabelece uma diferença entre um modo de exercício dessa masculinidade como domínio dos homens, para dizer que ela seria inquestionável na família no "Norte" ${ }^{6}$, no entanto, já relativiza esse domínio para o caso de sua família, em São Paulo. Em outros momentos da entrevista, a imagem de nordestino reafirma a visão do trabalhador com "coragem", vejamos um fragmento.

\footnotetext{
E por que são os nordestinos?

Porque o nordestino, ele procura em fazer alguma coisa que seja em benefício dele e da fábrica. Então o nordestino, ele topa tudo. [...] Então o nordestino vem prá cá, ele vem em torno disso aí. Só que tem um pequeno detalhe, também o metrô em São Paulo, os prédios em São Paulo, tudo nordestino, entendeu? Quantos nordestinos não morreram aí? Migrantes nas rodovias, é tanta coisa. Então, ali, 90\% que tava ali, o que eram? Nordestino! Se morreram oito lá, sete é nordestino. Isso aí eu tenho certeza. Por que? O nordestino é um cara que não tem medo de nada. É aquilo que eu te falei, é macho (Joaquim Bernardo, entrevista de 1984).
} 
Vemos nesse fragmento como a "coragem" para trabalhar se vincula a um ideal de masculinidade como sendo "macho". Conquanto nem sempre o termo "macho" esteja presente nas narrativas, os atributos de masculinidade são recorrentes e se expressam nas ideias de "coragem", força física, disposição para qualquer trabaIho. Assim, poderíamos dizer que essa noção mais ampla de masculinidade era um demarcador das representações identitárias dos trabalhadores que vêm da Região Nordeste para São Paulo.

Trata-se de uma construção identitária do nordestino como homem viril, forte, em outros termos, "macho". Como entender essa identidade masculinizada do nordestino? Por certo, não se trata de uma identidade "essencializada", mas sim construída historicamente. É com esta chave analítica que Durval Albuquerque Júnior (2000) demonstra como a identidade nordestina foi construída em torno da figura masculina.

O nordestino é uma figura que vem sendo desenhada e redesenhada por uma vasta produção cultural, desde o começo deste século $[X X]$. Figura em que se cruzam uma identidade regional e uma identidade de gênero. O nordestino é macho. Não há lugar nesta figura para qualquer atributo feminino. Na Região Nordeste até as mulheres são macho, sim senhor! Na historiografia e sociologia regionais, na literatura popular e erudita, na música, no teatro, nas declarações públicas de suas autoridades, o nordestino é produzido como uma figura de atributos masculinos (Albuquerque Júnior, 2000: 20).

Por aí podemos entender que essa representação identitária encontra assento na literatura, em jornais e folcloristas, sobretudo no período entre 1920 e 1940. É nesse início do século XX, período caracterizado pela transição de uma sociedade tradicional - rural e patriarcal - para uma sociedade moderna e urbana, em que sobressaem aqueles atributos de valentia e virilidade.

O nordestino seria macho pela própria história da região, que teria exigido a sobrevivência dos mais fortes, dos mais valentes e corajosos. Nessa descrição do nordestino, nós vamos perceber que, embora os intelectuais que estavam elaborando esse tipo regional estivessem ligados às elites, é no homem das camadas populares, principalmente do campo e do sertão, que se vai buscar um modelo típico de masculinidade para ser generalizado para todo ser regional. Os homens das elites decadentes, moles e impotentes, das novas elites burguesas, homens delicados e de punhos de renda, ou mesmo o morador pobre da cidade, efeminado por uma vida sem exercícios físicos duros, por uma vida que não era rústica, não serviam como modelo para esse novo homem que estava se pretendendo criar, capaz de significar uma resistência 
viril contra a cultura moderna e delicada que ameaçava descaracterizar a região e submetê-la definitivamente a outras áreas do país. Por isso é nos tipos rurais tradicionais e em sua cultura que se vai procurar o tipo regional e a cultura regional (Albuquerque Júnior, 2003: 202).

O argumento é discursivo, encabeçado por uma aristocracia rural decadente, em face da emergência de uma elite urbana, que cultiva outros hábitos. Mas, como ele frisa, o elemento viril idealmente representado é depositado numa caricatura do homem simples, trabalhador do campo. Como propõe Albuquerque Júnior (2003; 2005), é esse ideal de masculinidade, em que pese as mudanças ocorridas com a decadência da sociedade açucareira e patriarcal, que dá origem ao Nordeste moderno e que encontra apelo no comportamento violento, na imagem de que todo nordestino é hábil com facas.

Se a construção da identidade nordestina como masculina expressou um modo de afirmação da Região Nordeste em um contexto histórico em que a aristocracia rural estava perdendo poder, ela tem sido mobilizada no decorrer do século XX como construção identitária de trabalhadores pobres de áreas rurais do Nordeste que migraram para São Paulo. Os atributos de coragem, valentia, virilidade e força foram, de certo modo, armas de autovalorização para se contrapor à baixa, ou nenhuma, escolaridade e habilitações técnicas requeridas no mercado de trabalho urbano-industrial. E foi também, como já fizemos referência anteriormente, mobilizada por empresários e a imprensa da época para atrair trabalhadores e legitimar as condições de exploração intensa. Iremos abordar na próxima seção como esses atributos de masculinidade orientam a conduta dos trabalhadores em face das exigências da disciplina do trabalho nas indústrias metalúrgicas na Região do ABC Paulista.

\section{"Morre e não se entrega": \\ disciplina, humilhação e sofrimento}

A incorporação de um ideal de masculinidade se expressa nas formas de lidar com as condições de exploração e as formas de dominação nos espaços de trabalho. Iremos selecionar alguns fragmentos de entrevistas que narram a disciplina para o trabalho e o sentimento de "humilhação".

Filho de um pequeno proprietário, Marcos Silva nasceu em 1956, tinha 27 anos no momento da entrevista, em 1983, estava casado, com três filhos e trabalhava em uma metalúrgica de São Bernardo do Campo. Quando perguntado sobre São Paulo e os nordestinos, diz: 
Bem, é o seguinte. Tem muitos que vêm, vem só aquilo na cabeça, que às vezes o cara é mais ou menos lá e fala: "não, eu vou prá São Paulo". Aí chega aqui, quer viver uma vida, sabe, uma vida independente. Aqui o cara em São Paulo ele vive uma vida independente se ele for um cara que tiver uma boa condição, mas, se ele é um cara pobre, ele não pode viver uma vida independente, ele tem de viver uma vida humilhada. A vida humilhada assim, é, você vê, eu vim de lá prá cá, cheguei aqui tem, procurei uma firma, tô lá trabalhando, trabalhando, então, aí eu sou obrigado. Meu encarregado é um homem que só dava na minha cintura, a altura dele só dá aqui assim na minha cintura. Então, humilhado que eu falo é isso, eu falo, eu tô trabalhando num serviço, chega: "Ó, você vai fazer aquele outro". Eu não posso falar que não vou, não posso falar que vou deixar meu serviço que tô trabalhando prá fazer aquele outro serviço. Não, eu tenho de ir. Então, a obrigação, a humilhação que a gente fala é isso aí. A gente vive humilhado (Marcos Silva, entrevista de 1983).

Apesar da menor estatura, o chefe ocupa uma posição superior na hierarquia das relações de trabalho, o que subverte os atributos físicos da masculinidade associados àquele que manda. A despeito de ser um elemento mais difuso, a sujeição às regras de dominação do trabalho assalariado é representada como conduta: "ele não pode viver uma vida independente, ele tem de viver uma vida humilhada". Propomos duas leituras para o termo "humilhação" ou "vida humilhada". A primeira como expressão crítica às formas de controle e dominação do trabalho implementadas pelas chefias, que cerceiam a autonomia e a dignidade do trabalhador. A atitude de aparente aceitação às regras das empresas não necessariamente significa que o trabalhador é passivo, mas, antes, sugere uma atitude estratégica necessária para a manutenção do emprego, portanto é ativa. A luta pela permanência no emprego, isto é, para adquirir "anos de casa" e para conquistar uma "profissão" expressava-se, muitas vezes, na aceitação das regras de controle do trabalho como cumprimento das atividades segundo os critérios da hierarquia da empresa e obediência ao chefe-encarregado. O segundo aspecto que merece destaque é que "viver uma vida humilhada" é, nesse contexto, traduzido na chave da honra, do papel que se the espera na família como provedor.

Tem alguma outra humilhação em São Paulo que o nordestino passa?

Sobre ser nordestino não tem. Porque você sabe, o Nordeste é... O nordestino é brasileiro. Então, a humilhação que acontece é isso aí, em todo serviço. Você prá conseguir alguma coisa na vida, você tem de trabalhar, ser humilhado, entendeu? Talvez tem uma pessoa que às vezes, não, talvez, não seja igual a você, mas, às vezes, tem aquela chance, tem aquilo tudo, tem o supervisor na firma. 
Então, você tem que ser humilhado. Pelo nordestino, a força do braço do nordestino, mesmo com o nordestino ganhando seu dinheirinho. Mas, o nordestino são um pessoal que ele é, como é que se diz, ele morre e não se entrega, ele não abre do serviço, é um pessoal que pega qualquer serviço. Que toca o barco, o barco prá frente. É uma pessoa que tem coragem de trabalhar, é uma pessoa sofredora, acostumado a sofrer, assim, sofrer assim, trabaIhar, bastante (Marcos Silva, entrevista de 1983).

A necessidade de trabalhar e saber contemporizar com as regras de dominação é um valor que se sobrepõe ao sentimento de humilhação, ou seja, estar sob o comando, na maioria das vezes autoritário, das chefias (Rainho, 1980). Em sua pesquisa sobre as condições de trabalho dos metalúrgicos da Região do ABC Paulista, Laís Abramo (1999) analisa o desgaste físico e a tensão psicológica resultante da dilapidação das energias físicas e psíquicas dos trabalhadores. Nos relatos que ela colhe, os trabalhadores também expressam igual sentimento de humilhação e onipotência em razão das condições de trabalho na fábrica.

A narrativa sobre a humilhação como sentimento, percepção da disciplina e do controle do trabalho é recorrente na maioria das entrevistas que realizamos nas duas pesquisas. Ela se mistura com as imagens do trabalhador incansável, que "morre e não se entrega", que tem "coragem de trabalhar e está "acostumado a sofrer". Atributos que são constituintes da identidade nordestina do "macho" (Albuquerque, 1999) e do ideal de masculinidade da disciplina do trabalho (Palermo, 2017).

A percepção de que se trata de uma vida humilhada é seguida pela reafirmação da ideia de coragem e sofrimento - pessoa sofredora - acostumada a sofrer. Assim, poderíamos dizer que mesmo que expressem e tenham o sentimento de que se trata de uma vida humilhada, eles são homens fortes, "machos", estão acostumados a sofrer e por isso conseguem seguir em frente. Dessa forma, e este é o nosso argumento, a transmutação da humilhação e da dominação em honra e virtude permite que esses homens se sintam dignos. Daí a centralidade que o trabalho ocupa em suas vidas, como via de acesso aos atributos que constituem sua identidade e seu valor próprio.

Mas essa capacidade para suportar o sofrimento é interpretada nos achados de outros pesquisadores de maneira distinta. Assim, Rainho (1980) analisa um conjunto amplo de entrevistas com operários metalúrgicos identificados como peões do ABC Paulista sobre condições de trabalho no chão de fábrica, trajetórias de trabalho, moradia e consciência de classe. Na parte em que analisa a trajetória dos operários, ele destaca a origem rural, nordestina e o desejo de melhorar de vida. É nesse momento que ele identifica a lógica presente para suportar o sofrimento. 
O sofrimento é considerado elemento integrante e por isso comum à obtenção do que aspiram. Há, portanto, um grande desejo e coragem de alcançar tudo aquilo que chamam de "vencer e melhorar na vida". Trata-se, portanto, do mito do self-made-man inerente à própria fase pioneira de constituição do capitalismo (Rainho, 1980: 234).

Essa interpretação do sofrimento tem como fundamento teórico o conceito de classe. O suposto é do que esses trabalhadores não teriam formado "consciência de classe", pois concebem suas condições de trabalho e problemas como individuais, ou atribuem a crenças que reforçam uma mentalidade passiva, fatalista e conformista. Luís Rainho (1980) não mobiliza a categoria de gênero nem o ideal de masculinidade, o que é compreensível no período em que a pesquisa foi realizada, finais da década de 1970, em que havia uma onda de estudos sobre a classe trabalhadora e apenas emergiam algumas pesquisas com o recorte sobre as relações de gênero, a maioria de mulheres pesquisadoras ${ }^{7}$.

Já para Palermo (2017), a capacidade para aguentar sofrimento é analisada na pesquisa sobre petroleiros na Argentina em outra chave.

Un hombre petrolero debe exhibir cualidades como la resistencia al sufrimiento y para ello es imperioso que haya atravesado experiencias de sufrimiento en el pasado; debe saber soportar los golpes y sobre todo saber ser un hombre duro, lo contrario a un "pibe blandito". Ser "duro" es aceptar el absurdo privilegio de la masculinidad que impone a todo hombre el deber de afirmar su virilidad ante cualquier circunstancia. Ser duro expresa la exaltación de valores masculinos que van concretando los sentidos solicitados por la disciplina fabril (Palermo, 2017: 88).

A análise de Palermo interpreta a resistência ao sofrimento como demonstração da masculinidade dos petroleiros; deles se espera que sejam fortes e duros diante das situações dolorosas, de exaustão de seus corpos. Ser capaz de aguentar o trabalho pesado e a dura jornada de trabalho na extração de petróleo é um modo de afirmação cotidiana de valores masculinos que são requeridos pela disciplina fabril.

Ao colocarmos as interpretações de Rainho (1980) e de Palermo (2017) em diálogo, não temos como propósito identificar qual delas seria a mais apropriada para compreender a experiência de sofrimento relatada pelos operários metalúrgicos no ABC Paulista e pelos petroleiros na Argentina, mas, a contrapelo, expor como os argumentos contidos nas escolhas conceituais e teóricas - no caso o conceito de classe e relações de gênero - resultam em explicações bem diferenciadas das narrativas de resistência ao sofrimento.
7. Há um primoroso resumo da sociologia do trabalho industrial no Brasil de Nadya Guimarães (2004). 


\section{Considerações finais}

Revisitar as entrevistas feitas há 30 anos colocando-as em diálogo com achados mais recentes, nossos e de outros pesquisadores, e propondo uma releitura por meio de outras categorias de análise, só é possível com uma estratégia metodológica que estabeleça os parâmetros dessa aproximação. Se a nossa pretensão é a de um estudo de tipo longitudinal (Safi, 2015), que reconstitui sequências de acontecimentos e permite acompanhar a trajetória ocupacional de clusters de trabalhadores migrantes com origem rural e sua inserção nas indústrias da Região do ABC Paulista, ousamos inserir novas questões para dar tratamento ao material já colhido. Saber que os relatos resultavam de objetivos distintos, como explicamos no início do texto, constituía um limite metodológico para o experimento e, ao mesmo tempo, atuava como uma espécie de espada de Dâmocles em nossas cabeças a alertar-nos sobre os riscos do anacronismo.

Logo percebemos que o emprego da categoria de classe para interpretar trajetórias de migração e trabalho acabou deixando na penumbra a clivagem de gênero. Tendo colhido relatos de homens, não era possível repensar as mesmas trajetórias ago-

8. Fizemos isso em Santos Junior \& Menezes (2019). ra vistas sobre o prisma das mulheres (esposas e/ou trabalhadoras) ${ }^{8}$. A novidade estava em se debruçar sobre as entrevistas e fazer novas perguntas, confessando, para tanto, a inspiração teórica principal que havia motivado essa reflexão. E ela surge no afã de compreender a construção de masculinidades nesses coletivos de trabalho.

O deslocamento analítico tornava legível o tipo de performance requerida para sagrar-se homem nesse meio. $\mathrm{O}$ argumento lança mão da hipótese de que a autoridade masculina, e os processos de legitimação a ela associados, estão desigualmente distribuídos entre os trabalhadores homens. O que sugere que nem todos performavam os requisitos necessários. Enquanto ideal, uma vez que as representações associadas à figura do "macho" se alimentam do quadro social mais amplo no qual estão inseridos esses indivíduos, não estamos falando apenas de práticas sociais de efetivação dos atributos requeridos, mas igualmente das configurações discursivas que aninham modos de afirmação. Vimos, assim, como importava dar testemunho da força física pari passu veicular no discurso uma "narrativa de si" (Ricœur, 1994) em torno da figura do "nordestino".

Mas esta autorrepresentação não atinge o seu limite como expressão de uma suposta passividade (ou seria falta de consciência de classe?) dos trabalhadores cujas histórias analisamos, encerrando-se como um exclusivo-explicativo que a entende apenas pelo prisma da efetividade do consentimento das formas de dominação da 
disciplina fabril. Longe disso, o argumento que lançamos recupera a pista deixada por Lamont (2000) para dizer que as ambiguidades dos elementos probatórios dessa masculinidade, com a força do simbolismo ideal-típico que intitula uma região - o Nordeste - como provedora de indivíduos viris, assume a feição de construção da honra e da dignidade nas trajetórias desses trabalhadores. Este empenho em provar-se a si mesmo e aos outros, ainda que mais discursivo - lembremo-nos dos relatos de humilhação -, serviria para aplainar uma imagem de "bom trabalhador" e dar sentido às trajetórias de vida. Não tendo as habilidades técnicas requeridas para o trabalho na indústria, a provação é mobilizada como valor a ser reconhecido. É claro que, como vimos, as chefias também se valerão desse expediente para aumentar o controle. Quem cede, é para melhor controlar. Quem aceita, é para melhor viver.

Há, por fim, o aspecto geracional que se mostra decisivo nessas trajetórias. Se parece legítimo essa forma de armar questões, não se quer olvidar que estamos falando de uma geração de trabalhadores marcados por esse modo de representar o trabalho nas metalúrgicas, cuja expressão maior é a identidade de "peão". Já houve avanços significativos na literatura (Tomizaki, 2005; Santos Júnior, Thibes \& Menezes, 2019) que nos permitem afirmar que esse ideal de masculinidade já não é mais o mesmo, por conseguinte, mudaram também as estratégias de construção da dignidade do trabalhador. Mas isto já seria tema para outra pesquisa.

\section{Referências}

ABRAMO, Laís. W. O resgate da dignidade: greve metalúrgica e subjetividade operária. Campinas, SP: Editora Unicamp; Imprensa Oficial, 1999.

ALBERTI, Verena. Além das versões: possibilidades da narrativa em entrevistas de história oral. In: . Ouvir contar. Textos em história oral. Rio de Janeiro: Editora FGV, 2004.

ALBUQUERQUE JÚNIOR, Durval. M. De fogo morto: mudança social e crise dos padrões tradicionais de masculinidade no Nordeste no começo do século XX. História Revista (UFG), v. 10, n. 1, p. 153-181, 2005. Disponível em: <https://doi. org/10.5216/hr.v10i1.10103>.

. Nordestino: uma invenção do falo. Uma história do gênero masculino (Nordeste - 1920-1940). Maceió: Edições Catavento, 2003.

Cabra macho, sim senhor! Identidade regional e identidade de gênero no Nordeste. Territórios e Fronteiras, v. 1, n. 1, p. 25-39, 2000. 
Quem é froxo não se mete: violência e masculinidade como elementos constitutivos da imagem do nordestino. Projeto História (PUCSP), v. 19, p. 173-188, 1999.

ARCHER, Margaret. Culture and agency: the place of culture in social theory. Cambridge, UK: Cambridge University Press, 1996.

BOSI, Ecléa. Memória e sociedade: lembranças de velhos. São Paulo: Companhia das Letras, 1994.

BOURDIEU, Pierre. Practical reason. On the theory of action. Stanford, CA: Stanford University Press, 1998.

CERTEAU, Michel. A invenção do cotidiano: artes de fazer. Petrópolis, RJ: Vozes, 1994.

COVER, Maciel. "Andar pelo mundo" e "andar pelo sítio": migração, trabalho e territorialidade de famílias de agricultores do sertão paraibano. Tese (Doutorado em Ciências Sociais) - Programa de Pós-Graduação em Ciências Sociais, Universidade Federal de Campina Grande, Campina Grande, Paraíba, 2015.

FONTES, Paulo. Um Nordeste em São Paulo. Trabalhadores migrantes em São Miguel Paulista (1945-66). Rio de Janeiro: Editora FGV, 2008.

Migração nordestina e experiências operárias. São Miguel Paulista nos anos 1950. In: BATALHA, Claudio H. M.; SILVA, Fernando T.; FORTES, Alexandre (Orgs.). Culturas de classe: identidade e diversidade na formação do operariado. Campinas, SP: Editora Unicamp, 2004.

FRENCH, John D.; CLUFF, Mary Lynn P. As mulheres e a mobilização operária na época de pós-guerra em São Paulo, 1945-1948. História Social, n. 7, p. 171-211, 2000.

GUIMARÃES, Nadya A. Caminhos cruzados. Estratégias de empresas e trajetórias de trabalhadores. São Paulo: Editora 34, 2004.

HALBWACHS. Maurice. A memória coletiva. São Paulo: Vértice, 2006.

HUMPHREY, John. Sindicato: um mundo masculino. Novos Estudos Cebrap, v. 2, n. 1, p. 47-52, 1983.

LAMONT, Michèle. The diginity of working man: morality and boundaries of race, class, and immigration. Cambridge, MA: Cambridge University Press, 2000.

LOPES, Juarez B. Crise do Brasil arcaico. São Paulo: Difel, 1967. 
MENEZES, Marilda A. de. A migração Nordeste-São Paulo e a memória dos trabalhadores do ABC Paulista. In: LEITE LOPES, José S.; HEREDIA, Beatriz (Orgs.). Trabalhadores urbanos, trabalhadores rurais: história e perspectivas. Rio de Janeiro: Editora UFRJ, 2019.

Redes e enredos nas trilhas dos migrantes. Um estudo de familias de camponeses-migrantes. Rio de Janeiro: Relume Dumará, 2002.

Da Paraíba prá São Paulo e de São Paulo prá Paraíba: migração, família e reprodução da força-de-trabalho. Dissertação (Mestrado em Sociologia Rural) - Departamento de Ciências Sociais, Universidade Federal da Paraíba, Campina Grande, 1985.

NEGRO, Antonio. L. Zé Brasil foi ser peão. Sobre a dignidade do trabalhador não qualificado na fábrica automobilística. In: BATALHA, Claudio H. M.; SILVA, Fernando T. da; FORTES, Alexandre (Orgs.). Culturas de classe: identidade e diversidade na formação do operariado. Campinas, SP: Editora Unicamp, 2004.

PAIVA, Rita de Cássia Souza. O discurso e a ação: a volta do ator e a narração como opção metodológica. Plural: Sociologia USP, n. 6, p. 76-102, 1999.

PALERMO, Hernán M. La producción de la masculinidad en el trabajo petrolero. Buenos Aires: Biblos, 2017.

PORTELLI, Alessandro. O que faz a história oral diferente. Projeto História, n. 14, p. 25-39, Fev. 1997.

RAINHO, Luís F. Os peões do Grande ABC. Petrópolis, RJ: Vozes, 1980.

RICCEUR, Paul. Onself as another. Chicago, IL: The University of Chicago Press, 1994.

RODGERS, Daniel T. The work ethic in industrial America, 1850-1920. Chicago, IL: University of Chicago Press, 1974.

SAFI, Mirna. A dimensão temporal dos fatos sociais: a pesquisa longitudinal. In: PAUGAM, Serge (Org.). A pesquisa sociológica. Petrópolis, RJ: Vozes, 2015.

SAFFIOTI, Heleieth. A mulher na sociedade de classes: mito e realidade. Petrópolis, RJ: Vozes, 1970.

SANTOS JUNIOR, Jaime; THIBES, Mariana Z.; MENEZES, Marilda A. de. Disjunções e ambivalências: famílias migrantes nordestinas no ABC Paulista. Civitas, Rev. Ciênc. Soc., v. 19, n. 3, p. 675-691, Dez. 2019. Disponível em: <https://doi. org/10.15448/1984-7289.2019.3.28647>. 
SANTOS JUNIOR, Jaime; MENEZES, Marilda A. de. À margem da história? Mulheres metalúrgicas e a memória das greves do ABC (1978-1983). In: LEITE LOPES, José S.; HEREDIA, Beatriz (Orgs.). Movimentos cruzados, histórias específicas. Rio de Janeiro: Editora UFRJ, 2019.

THIBES, Mariana Z.; MENEZES, Marilda A. de; SANTOS JUNIOR, Jaime. Narrativas assimétricas: gênero, família e trabalho no ABC Paulista. Sociologia \& Antropologia, v. 8, n. 2, p. 519-541, Ago. 2018. Disponível em: <https://doi.org/10.1590/ 2238-38752017v827>.

TOMIZAKI, Kimi A. Envelhecer na fábrica: a redefinição da identidade dos metalúrgicos do ABC nos anos 90. Caxambu, MG: Anais XXIX Encontro Anual da Anpocs, 2005. Disponível em: <https://www.anpocs.com/index.php/encontros/papers/29-encontro-anual-da-anpocs/gt-25/gt26-6>. 